ISSN: 0213-2079 - ISSN electrónico: 2386-3889

DOI: https://doi.org/10.14201/shhmo20163822754

\title{
TUTELA Y MINORÍA DE EDAD EN LA CASTILLA RURAL: PRÁCTICAS COTIDIANAS DE ANTIGUO RÉGIMEN*
}

\section{Guardianship and Minority Protection in Rural Castile: Daily Practices of Ancient Régime}

\author{
Máximo GARCÍA FERNÁNDEZ \\ Universidad de Valladolid \\ Correo-e: mgarcia@fyl.uva.es
}

RESUMEN: Entre los estudios sobre el 'ciclo de vida' el tema de la minoría de edad en la Castilla rural en la evolución de sus significados a lo largo de la época Moderna merece un capítulo especial. En aquella larga etapa vital sin márgenes muy precisos, el conocimiento de la práctica de la tutela y la curaduría legal de los jóvenes resulta capital para comprender periodos muy críticos dentro de los entornos familiares. No se trataba de un problema menor ni escaso cuando afectaba a todos los sectores sociales durante largos periodos de tiempo y por motivos universales relacionados con la protección de la enorme cantidad de huérfanos necesitados de defensa para que el mantenimiento de sus patrimonios les permitiera su supervivencia alimenticia y de vestuario primero, su matrimonio años después y sus posibilidades de medro y ascenso económico o cultural siempre. La

* Trabajo encuadrado dentro del Proyecto de Investigación financiado por el Ministerio de Economía y Competitividad (HAR2013-48901-C6-3-R, 2014-2017): Civilización, juventud y cultura material e inmaterial. Familia e identidad social. Demandas y apariencias en la Castilla interior. 1500-1850. Remitimos a la próxima aparición de la obra: GARCía Fernández, M.: Los Caminos de la Juventud en la Castilla Moderna. Menores y Huérfanos: Tutorías y Curadurías [en prensa]. 
MÁXIMO GARCÍA FERNÁNDEZ

TUTELA Y MINORÍA DE EDAD EN LA CASTILLA RURAL: PRÁCTICAS COTIDIANAS DE ANTIGUO RÉGIMEN

cotidianeidad de aquellas existencias dependía de las distintas actuaciones tutoriales.

Palabras clave: Tutoría legal; Juventud; Castilla rural; Antiguo Régimen.

ABSTRACT: Among the studies on the 'life cycle' the issue of the minority in rural Castile in the evolution of their meaning throughout the modern era deserves a special chapter. In that long life stage without very precise margins, knowledge of the practice of legal guardianship and curatorship of young people is very critical capital to understand within family environments periods. It was not a minor or little problem when it affected all social sectors for long time and universal reasons relating to the protection of the huge number of needy orphans of defense for maintaining their assets and heritage allow survival, their marriage and their ability to thrive and always economic or cultural promotion. The daily life of those stocks depended on the different tutorials performances.

Key words: Legal Guardianship; Youth; Rural Castile; Ancient Régime.

\section{HUÉRFANOS Y MENORES: PLANTEAMIENTOS}

Cuando ya se investigan tantos aspectos sobre la vejez y otras etapas de la vida, urge adentrarse en el conocimiento de la juventud. Desatendida hasta ahora por buena parte del Modernismo europeo, muchas son las preguntas y respuestas aún por concretar y esclarecer. Unas vivencias juveniles tras la supervivencia infantil centradas aquí en la mayoría popular rural. Desde enfoques y planteamientos muy diferentes: a ellas «no las queremos tan doctas como honestas», mientras que respecto a los mozos renacentistas «amigo, yo he de criar / soldados y no confites», mostrando claros contrastes de género entre la sumisión y el prestigio de las armas, cuando ya en el ilustrado siglo XviI prevalecería ser para un mayor número de todos ellos «muchachos de buenas prendas y muestras... entrando con afición al estudio».

Muchas y variadas fuentes documentales informan de forma indirecta sobre la juventud castellana. Aun así, junto a algunas obras que tratan estos aspectos de forma tangencial, las de referencia son escasas ${ }^{1}$; y lo mismo puede decirse sobre

1. Levi, G. y Schmitt, J. C. (Dirs.): Historia de los jóvenes, vol. I: De la Antigüedad a la Edad Moderna. Madrid, 1996; SAAvedra Fernández, P.: La vida cotidiana en la Galicia del Antiguo 
MÁXIMO GARCÍA FERNÁNDEZ

TUTELA Y MINORÍA DE EDAD EN LA CASTILLA RURAL: PRÁCTICAS COTIDIANAS DE ANTIGUO RÉGIMEN

lo exiguo de las monografías centradas en el sistema de tutoría, donde destaca la aportación de la doctora Cava². Tras el rastreo sistemático de la bibliografía vinculada al mundo juvenil español o europeo ${ }^{3}$ se concluye que no abundan los libros sobre este campo histórico.

El que planteamos como 'índice' (pionero aunque criticado) se debe a Philippe Ariès ${ }^{4}$. «No hubo espacio para la infancia hasta el siglo xviI», concluía. Era la edad de la escuela. Con una confusión terminológica de infancia-adolescencia, mezclando el aprendizaje y la transmisión de los saberes de generación en generación con la educación, hasta que, saliendo de la esfera del hogar, fue extendiéndose la frecuencia de la práctica escolar, masculina, empezando por los jóvenes privilegiados urbanos. Una instrucción sacra y cívica a la vez de cara a la promoción ascendente de todo aquel que aspirase a la condición civilizada de ciudadano.

A esas edades, formación y problemas financieros se convertían en el centro de atención familiar en torno a aquellos mozos-as. De ese modo, la libertad de acción de los interesados quedaba muy disminuida, máxime cuando muchas prácticas se centraban en una férrea pedagogía de la disciplina y la autoridad paterna y la consiguiente obediencia infantil, aconsejando evitar cualquier indulgencia. Todo lo cual no evitaba la existencia de conflictos intrafamiliares. Para todos los implicados, las palabras clave eran formación espiritual e instrucción escolar y/o laboral de cara al matrimonio 5 . Pero con los hijos también llegaban las responsabilidades derivadas

Régimen. Barcelona, 1994; Kertzer, D. I. y Barbagli, M. (comps.): Historia de la familia europea, vol. I: La vida familiar a principios de la era moderna (1500-1789). Barcelona, 2002; y REDONDO, A. (Ed.): La formation de l'enfant en Espagne aux Xvie et XVIIe siècles. París, 1996.

2. Cava López, M. ${ }^{a}$ G.: Infancia y sociedad en la Alta Extremadura durante el Antiguo Régimen. Cáceres, 2000 (tesis doctoral inédita); de la misma autora: «La tutela de los menores en Extremadura durante la Edad Moderna», Revista de Historia Moderna, 18, 2000, pp. 265-288. Un trabajo muy pormenorizado, centrado en la designación de tutores en el norte de la actual provincia de Cáceres.

3. Bouneau, Ch. y Le Mao, C. (Dirs.): Jeunesse(s) et élites. Des rapports paradosaux en Europe de l'Ancien Régime à nos jours. Presses Universitaires de Rennes, 2009; RoberTs, B. B.: «The 'Marlboro Men' of the Early Seventeenth-Century. Masculine Role Models for Dutch Youths in the Golden Age?», Men and Masculinities, 9, julio 2006, pp. 76-94; Fass, P. S. (Ed.): The Encyclopedia of the History of Childhood. Nueva York, 2003; Roberts, B. y Groenendijk, L.: "Moral Panic and Holland's Libertine Youth of the 1650s and 1660s", Journal of Family History, 30, 2005, pp. 327-346; y Roberts, B.: «'Wearing Out a Pair of Fool's Shoes'. Sexual Advice for Youth in Holland's Golden Age», Journal of the History of Sexuality, 13, 2004, pp. 139-156.

4. ArIÈs, Ph.: El niño y la vida familiar en el Antiguo Régimen. Madrid, 1987 (1. a edición 1960)

5. Ago, R.: «Jóvenes nobles en la época del absolutismo: autoritarismo paterno y libertad», en Levi, G. y Schmitt, J. C.: op. cit., pp. 365-413. 
MÁXIMO GARCÍA FERNÁNDEZ

TUTELA Y MINORÍA DE EDAD EN LA CASTILLA RURAL:

PRÁCTICAS COTIDIANAS DE ANTIGUO RÉGIMEN

de la conservación y aumento de los patrimonios, y, con mucha frecuencia, las orfandades y la necesidad de nombrar tutores o defensores de dichos menores. Se entremezclaban entonces cuestiones hereditarias con otras de inclusión en el mundo productivo y el signo de los avances educativos mirando también a la mejor de las alianzas maritales posibles ${ }^{6}$. Todas de enorme interés y que suscitaron enormes intereses.

También desde la perspectiva de la cultura material interesa replantear aquí aspectos ciertamente importantes, hasta el momento escasamente tenidos en cuenta, y ligados a las pautas y criterios motores de la demanda juvenil campesina, con sus propios ritmos de reposición, necesidades, gustos y tendencias a la adquisición y lucimiento de nuevas modas. Puesto que la mocedad podía condicionar la generación de hábitos novedosos, la propensión al cambio de vestido -y de mentalidad-se agudizaría entonces entre aquellos menores de edad cuando su situación de orfandad les obligaba a trasladar su forma de vida familiar originaria hacia el aprendizaje gremial o el estudio urbanos. La cantidad, variedad, novedad y calidad del recuento de los productos semiperecederos, heredados o adquiridos durante esos años en el mercado, permitirán mostrar algunas de las claves de sus tendencias consumistas - $\mathrm{O}$ no- a lo largo del Antiguo Régimen, cuando las cuentas de curaduría castellanas pueden proporcionar valiosa información sobre los principales capítulos del desembolso monetario al que debieron hacer frente entonces los tutores.

Así, desde esta nueva óptica que reformula la historia de la familia, y poniendo énfasis en tres ángulos aún poco contrastados hasta ahora, lo rural, lo popular y lo juvenil, se profundiza en las transformaciones operadas en el consumo específico del traje adquirido (y en el ajuar femenino) para vestir a aquellos menores de edad y establecer las variaciones de su peso relativo en la demanda del conjunto familiar junto con las razones a que obedecieron (cambios en el gusto, imitación social o exigencia obligada por viajes fuera de su ámbito de origen). El avance del sentido moderno de las necesidades individuales dio lugar a concepciones alternativas tanto de la apariencia como del espacio doméstico, generando estímulos para aquellas adquisiciones textiles. El envío de jóvenes procedentes del mundo campesino hacia el estudio o el sacerdocio urbanos pudo modificar sus hábitos consumistas tradicionales. Por emulación, la sociabilidad burguesa animó también la generalización de nuevas pautas juveniles.

6. Arbiol, A.: La familia regulada, con doctrina de la Sagrada Escritura. Madrid, 1715. 
Giro ideológico, juventud y demostración consumista generarían lucimiento y movilidad contrastados. Interesa relacionar, así, al 'individuo ilustrado' y al 'antiguo', jóvenes y mayores, con los nuevos conceptos de buen gusto, emulación, civilización o lujo... y con las decisiones tomadas por los tutores respecto al inmediato futuro de los menores a su cargo, desde la perspectiva de que podían definir avances sustanciales en la concepción de la demanda y en la frecuencia del ritmo de sus adquisiciones desde su etapa juvenil o, por el contrario, mantener prácticas tradicionales de contención del gasto en cuanto a más, variadas y mejores vestimentas. En concreto, aquí se propone el inicio del estudio de los pleitos por el control testamentario y hereditario más los ritmos de reposición de los ajuares familiares a partir de los gastos de tutoría y curaduría de menores, en la medida en que de sus decisiones y actuación cabe deducir avances modernizadores o enormes frenos anclados en la tradición.

En suma, vidas familiares simbólicas, desde donde emergería la idea de la construcción diferenciada de identidades juveniles, de género u ocupacionales, revalorizando el papel jugado entonces por los jóvenes (y sus tutores legales) en tal proceso, al remarcar que aquellas minorías de edad en la Castilla rural moderna constituyen un capítulo clave en 'el ciclo de vida' al afectar a todos los sectores sociales durante largos periodos de tiempo para la protección de la enorme cantidad de huérfanos necesitados de defensa, alimenticia primero y ocupacional y matrimonial años después; siempre desde la cotidianeidad de cubrir sus necesidades vestimentarias.

\section{LA DESIGNACIÓN DE TUTORES Y CURADORES: AL CUIDADO FÍSICO Y MORAL DE} LOS MENORES Y DE SUS INTERESES

La familia era el espacio jurídicamente regulado de la patria potestad paterna para el control de las haciendas ${ }^{7}$. La legalidad y la práctica convirtieron en habitual el recurso a aquel sistema de protección cada vez más extendido socialmente ${ }^{8}$.

Legítimos o dativos, los defensores testamentarios ampliaron así sus funciones. Pero pese al esfuerzo de control que traducen dichas medidas, los abusos y demoras en el ejercicio de ciertos deberes (principalmente la presentación y entrega del balance contable a los interesados) también debieron ser frecuentes, como

7. Rodríguez SÁnchez, Á.: «El poder familiar: la Patria Potestad en el Antiguo Régimen», Crónica Nova, 18, 1990, pp. 365-380.

8. Melgarejo, P.: Compendio de Contratos Públicos, autos de particiones. Madrid, 1704 (1674). Libro Segundo: 'De tutelas, inventarios y todo género de particiones y cuentas'; y 'Tutores', pp. 237-244. 
MÁXIMO GARCÍA FERNÁNDEZ

TUTELA Y MINORÍA DE EDAD EN LA CASTILLA RURAL: PRÁCTICAS COTIDIANAS DE ANTIGUO RÉGIMEN

muestran los numerosos requerimientos presentados ante la justicia para exigir su cumplimiento o las cautelas manifestadas por los progenitores en sus testamentos.

Más allá del objetivo de lograr una protección idónea de la persona del menor, la tutela se centraba en el interés patrimonial de todos los consanguíneos, por cuanto tutorías y curadurías se convirtieron en instrumentos esenciales de dominio y gobierno de las haciendas domésticas. Resultaba relevante entonces la identidad de la persona(as) de confianza en la cual recaería la gestión de tales herencias, así como el grado de intervención e interés de los allegados en las ocasiones en las que se requería su colaboración en las asambleas o juntas de parientes, constituidas para resolver la designación de los defensores de aquellos huérfanos (estrategia ampliamente conocida para el caso francés ${ }^{9}$, pero que en Castilla apenas se atestigua $)^{10}$. No obstante, las referencias documentales conservadas ofrecen noticias sobre los esfuerzos acometidos por los familiares más cercanos al pupilo por mantener una influencia directa sobre aquellas 'legítimas', alejándolos de toda intromisión externa. Con esa idea de fondo aparecían no pocas peticiones de algunas madres que, pese a haber contraído segundas nupcias, reclamaban para sí la custodia de sus hijos y bienes o la de aquellos hermanos que pretendían idénticos fines en detrimento de los tutores establecidos. A la ayuda a los menores se unía entonces el celo por el control patrimonial de la casa, cuando no un claro intento de aprovechamiento lucrativo personal en menoscabo del legítimo provecho de las posibilidades presentes y futuras de aquellos jóvenes.

El celo en las decisiones adoptadas en esta materia por la familia se evidencia en el creciente volumen de nombramientos de tutores por parte de los progenitores de tutores por orden testamentaria (y tras las declaraciones de sus intenciones justificativas). En esta línea, las manifestaciones de satisfacción y confianza en el buen trato hacia el menor y en la gestión leal y eficaz del patrimonio que se esperaban obtener del individuo señalado fueron referencia común en aquellas cláusulas en las que se instituían, junto a los testimonios de rechazo a cualquier intromisión de extraños o de las propias autoridades judiciales, siempre temidas por las dilaciones que solían generar o por su mera injerencia en la administración de los caudales.

9. Pierrer, S.: «Roles des réseaux de parenté dans l'education des mineurs orphelins selon les comptes de tutelle parisiens (Xvire-XviIIe siécles)», Annales de Démographie Historique, 1995, pp. 125-135.

10. Véase: Historique (1995), Cava López, M. ${ }^{a}$ G.: «La protección familiar a la infancia desamparada: huérfanos en Extremadura en tiempos de Felipe II», Martínez Ruiz, E. (Dir.): Madrid, Felipe II y las cindades de la Monarquía. Madrid, 2000, pp. 83-96. 
En todo caso, en la Europa occidental rural de antiguo régimen se ponía de manifiesto la necesidad del concepto tutorial, de cara a evitar la pérdida de los bienes muebles de aquellos mozos: al incluir también ganados y aperos de labranza - «que podrían morir y deteriorarse en perjuicio de los menores»- adquirían un carácter más social y protector sobre sus herencias raíces que las urbanas. La ratificación por vía testamentaria de la tutela en la figura de la madre suponía el mantenimiento de las condiciones de vida material del niño en su ámbito doméstico y dentro de un clima de aparente continuidad familiar. La mayoritaria elección por los varones de sus esposas en tanto mantuviesen su viudedad (junto a la cesión del usufructo de la hacienda en favor de aquellas, previo su compromiso de asumir la crianza y educación del joven, aunque no fuesen designadas explícitamente como tutoras y curadoras del mismo) también advierte de una progresiva intención paterna de defender los vínculos parentelares en favor de la atención afectiva de aquellas minorías de edad.

Así, en la Castilla moderna rural la documentación aporta numerosos ejemplos a priori legalmente anómalos pero comúnmente aceptados en la práctica cotidiana. De esta manera, la realidad refleja un incremento de la aceptación por parte de amplios colectivos sociales de la tutoría reclamada por la madre nuevamente casada. Dichas disposiciones de confianza en el provecho de los intereses de los huérfanos revelan el reconocimiento de la labor educativa, afectiva y administrativa que se esperaba de ellas. Por el contrario, la autoridad y cuidados de un tutor diferente al progenitor no siempre fueron óptimos y las cuentas finalmente firmadas muestran lo necesario de su estricto control, lo mismo que se multiplicaban los litigios con respecto a la presencia temporal o permanente del menor en el domicilio de aquel (cuando sus trabajos podían supeditarse a menudo a la remuneración de los gastos de manutención presupuestados por la autoridad competente).

Más allá de las leyes (y del sistema de garantías para aquellos huérfanos), el interés se centraba entonces en las redes de solidaridad tejidas en torno a los menores. A tal objeto, los testamentos y las actas notariales derivadas del proceso de discernimiento y aprobación tutelar que trataba de solventar la sensible cuestión de la atención patrimonial y personal juvenil resultan claves para comprender el papel de la infancia en un mundo de adultos, estudiar el protagonismo femenino $\mathrm{y}$ acercarse a la personalidad del resto de los depositarios o a los problemas materiales derivados de su control.

El constante incremento de los testamentos en los que se nombraba directamente a los tutores permite constatar (a la par que el debilitamiento de las relaciones comunitarias) los progresos que experimentó el trato dispensado al joven dentro de su familia. Las tutelas ordenadas en las últimas voluntades aumentaron con una tendencia consolidada en la segunda mitad del siglo XviII (con un progreso paralelo 
en Valladolid ciudad y sus áreas rurales y próximo al registrado en Santiago de Compostela $a^{11}$, Zamora $^{12}$ o en la comarca extremeña de Coria $\left.{ }^{13}\right)$ : paulatinamente se intensificaba un cambio de actitud en la consideración de la infancia, enlazada con la necesidad de contar con suficientes instrumentos para garantizar su protección.

Entonces, el protagonismo femenino (conyugal) fue un rasgo notable y constante de los tutores nominados -mujeres sobre las que recayeron siempre más de las dos terceras partes de los nombramientos-, aunque, incluso, presentasen una paulatina disminución en consonancia con la mayor participación de otros miembros masculinos del grupo familiar, y debido al creciente peso de las elecciones efectuadas por las madres testadoras (tabla n. ${ }^{\circ} 1$ ). Todo lo cual sugiere un proceso de retraimiento de las solidaridades en el seno doméstico extenso en beneficio de la mayor confianza mostrada hacia los miembros de la unidad nuclear, indicio del nacimiento y consolidación de una familia moderna que apuntaba hacia una progresiva concentración de los apoyos y las relaciones afectivas y asistenciales en el agregado troncal más próximo.

En la tutela campesina gallega, por ejemplo, se aparecían más negativas expresas de tíos y primos de los jóvenes a asumir la responsabilidad de tales cargos para cuando debieran ofrecer finalmente el balance de su gestión llegada la mayoría de edad legal, todo lo cual justificaba una mayor presencia allí de vecinos y extraños al universo familiar en este cometido (hasta un $11 \%$ ); de ahí también que en no pocas ocasiones solo se aceptasen tales designaciones bajo el apremio de los tribunales y las autoridades competentes ${ }^{14}$. Algo parecido a lo que ocurría en la provincia de Valladolid ${ }^{15}$, donde, constatando notables contrastes entre la ciudad y su zona rural circundante en cuanto al nombramiento de aquellos tutores y curadores, la realidad que se imponía pasaba por una tutoría materna arropada por el cúmulo de familiares más próximos existentes, sin olvidar, máxime entre el colectivo femenino, en los entornos el entorno periurbanos y a medida que se acercaba el siglo XIX, una relativa fuerza de la presencia activa de vecinos, miembros de la abogacía local versados en leyes y clérigos conocidos (todos ellos de «cristianísimos ánimos

11. Dubert García, I.: Historia de la Familia en Galicia durante la época Moderna, 15501830. La Coruña, 1992.

12. Lorenzo Pinar, F. J.: «La familia y la herencia en la Edad Moderna zamorana a través de los testamentos», Studia Historica. Historia Moderna, 9, 1991, pp. 159-201.

13. Cava López, M. ${ }^{a}$ G.: «La tutela...», art. cit., pp. 265-270.

14. Dubert García, I.: op. cit.; 'Tutela, Familia, Infancia y Administración del patrimonio', pp. 241-250.

15. García Fernández, M.: Herencia y patrimonio familiar en la Castilla del Antiguo Régimen (1650-1834): efectos socioeconómicos de la muerte y la partición de bienes. Valladolid, 1995, pp. 296-302. 
y probidad reconocida») que atestiguan la necesidad de seguir contando con el apoyo comunitario, el conocimiento legal vigente o una admitida capacidad universalmente aceptada de evitar cualquier conflicto sucesorio.

TABLA 1. Designación de tutores y curadores testamentarios por los testadores castellanos. Valladolid, siglo xviII (porcentajes)

$\begin{array}{lcccccc}\text { Tutores } & \text { Cónyuges } & \text { Hermanos } & \text { Hijos } & \text { Padres } & \text { Familiares } & \text { Otros } \\ 1700-1710 & 88,0 & 1,9 & 1,9 & 1,9 & 2,8 & 3,5 \\ 1790-1799 & 68,8 & 3,1 & 3,7 & 1,9 & 10,6 & 11,9 \\ & & & & & & \\ \text { Varones nombran a } & 90,5 & 1,7 & 1,2 & 0,7 & 3,3 & 2,6 \\ \text { Mujeres nombran a } & 21,1 & 8,4 & 7,4 & 9,5 & 35,8 & 17,8 \\ & & & & & & 10,7 \\ \text { Zona rural } & 71,5 & 3,8 & 3,4 & 2,1 & 8,1 & 2,8 \\ \text { Valladolid ciudad } & 83,0 & 2,1 & 1,4 & 2,5 & & \\ \text { Media Total } & 77,8 & 2,9 & 2,3 & 2,3 & 9,3 & 5,4\end{array}$

Fuente: AHPVa. Protocolos Notariales.

En suma, las ayudas a la orfandad desprotegida y la búsqueda de una buena crianza de la minoría de edad, máxime si se trataba de la femenina en el mundo urbano, cada vez era una realidad más habitual. De igual forma que también se advierte esa atención tutelar a las necesidades infantiles en la zona pinariega vallisoletana de Bocigas, donde, hacia 1730, por ejemplo a la muerte Francisco Alonso, don Laurencio de Zarza, procurador del número de Olmedo, siempre era nombrado curador ad litem de las personas y bienes de los menores sobrevivientes, encargado de convocar a todas las partes para formar el cuerpo de hacienda y las cuentas y particiones; como en otras muchas situaciones similares aceptaba el cargo ${ }^{16}$.

\section{Pleitos civiles ante las Chancillerías castellanas sobre tutorías y CURADURÍAS}

Aquel teórico cuidado de los intereses de los menores chocaba con la realidad de una alta frecuencia del litigio en torno a tales escenarios y contextos. Así, no pocos de aquellos controles contables acabaron en largos pleitos cuando alguno

16. Archivo Histórico Provincial de Valladolid [en adelante AHPVa], Sección de Protocolos Notariales [Secc. Prot.], leg. 11307, fol. 601-611. 
MÁXIMO GARCÍA FERNÁNDEZ

TUTELA Y MINORÍA DE EDAD EN LA CASTILLA RURAL: PRÁCTICAS COTIDIANAS DE ANTIGUO RÉGIMEN

de los implicados entendía que los tutores no habían cumplido lealmente con sus compromisos de salvaguarda, inversión y acrecentamiento de los patrimonios juveniles.

De estos hemos registrado más de un millar para toda la corona castellana entre 1501 y 1799 (1.207 pleitos). Lo cierto es que esperábamos obtener mayor información respecto a los consumos efectuados en las tutorías para satisfacer las necesidades de los menores de edad durante los largos periodos de tiempo que abarcaban aquellas reclamaciones. No es así. Analizado un porcentaje próximo al $25 \%$ del conjunto de esos registros, apenas unos pocos proporcionan datos de interés sobre gastos seriados en el surtido del vestuario juvenil. Infinidad de problemas de todo tipo, en cambio, surgen por doquier de esos testimonios; base documental sobre la que fundamentaremos ahora algunas conclusiones que consideramos relevantes y de interés (tablas n. ${ }^{\circ} 2$ y 3 ).

Se recuentan muchísimos en torno al reparto de las haciendas entre los diferentes hermanos al efectuarse las partijas y las particiones hereditarias. Dispersos por espacios urbanos y rurales, tanto en el centro como en la periferia norte peninsular, y sin una concentración cronológica clara, por mayorazgos o disputándose unos pobres dineros. Eran 'agravios por la rendición de cuentas de tutoría' o 'alcances y pagos de curaduría'. En suma, una gran cantidad de pleitos civiles que llegaron a la más altas instancias de las Reales Chancillerías sobre las «curadurías, tutorías, alimentos y ropajes» de aquellos jóvenes. Todavía durante el siglo XviII muchos casos ejemplares constatan una polifacética realidad que impedía a los menores disfrutar de una mayor liquidez para tratar de incrementar sus gastos y consumos por encima de su mera supervivencia ${ }^{17}$.

17. Por ejemplo: «Pleito de Pascual Arroyo Salvador, Josefa Fernández de Recalde y José Fernández de Recalde, todos de Lumbrales (Salamanca). Entrega a Pascual y a su mujer Josefa las cuentas procedentes de los once años en que José fue su curador»; Archivo de la Real Chancillería de Valladolid [en adelante ARChVa], Pleitos Civiles. Pérez Alonso, olvidados, caja 397,1 (1768-1774); «Pleito de Agustín de Llanos y Antonio Astorga, de La Bañeza (León). Agustín pedía a Antonio, administrador y curador de Fabián de Ujidos, repartir los bienes de este entre todos los herederos, ya que llevaba desaparecido más de 20 años»; ARChVa, Pleitos Civiles. Fernando Alonso, fenecidos, caja 3138,6 (1793-1797); «Pleito de José Vigil Jové, como curador ad litem de Jacinto García de Herrera, contra Joaquina M. a de Caso Álvarez, condesa de Nava, sobre si José García de Herrera, ya difunto y vecino y regidor de León, y, en su representación, Jacinto, como sucesor, heredero y llevador de varias caserías sitas en el concejo de Nava (Asturias), había de pagar o no a la citada condesa, como sucesor de Rodrigo de Caso, su usufructuario, las rentas que habían producido correspondientes a cinco años en que los había poseído»; ARChVa, Pleitos Civiles. Alonso Rodríguez, fenecidos, caja 2571,6 (1766-1769); «Pleito de Ramón Cocinero, padre y legítimo administrador de su hijo Plácido, de edad de 7 a 8 años, de Mucientes (Valladolid), contra Felipe Bastardo, labrador, su convecino, y 
Aquellas actuaciones populares en torno a las minorías de edad y los problemas subsiguientes derivados del cuidado de sus personas y patrimonios aumentaron su reiteración con el paso del tiempo de forma significativa en los espacios controlados por el tribunal de justicia granadino; todo lo contrario ocurría en el vallisoletano: aunque también a finales del siglo XviII volvieron a multiplicarse, más de la cuarta parte de aquellas causas suscitadas en la Meseta norte se concentraron en la segunda mitad del xvi. Eso sí, en ambas zonas los curadores (ad litem más que ad bonam) aparecieron involucrados muchísimo más habitualmente que los propios tutores.

Todos los datos presentados resultan aún provisionales. Aun así, entendemos que resultan ya enormemente significativos, toda vez que muestran una radiografía de la realidad de la minoría de edad castellana precisamente cuando surgían los problemas y las cuestiones. Es cierto que en numerosas ocasiones se litigaba por cantidades que pueden parecer ciertamente muy reducidas (menos de un millar de reales), pero por encima de cualquier valoración tangible estaban los derechos inalienables de aquellos mozos cuyas familias no podían consentir pérdida ni menoscabo alguno.

Tabla 2. Catálogo de pleitos suscitados ante la Real Audiencia y Chancillería de Valladolid (siglos XVI-XVIII)

$\begin{array}{rcl}\text { XVI-XVII } & \text { XVIII } & \text { Causas de los litigios } \\ 48 & 6 & \text { Rendir cuentas administración del tiempo tutoría (restitución de bienes) } \\ 21 & 1 & \text { Entre tutores y curadores por mala administración de minorías de edad } \\ 2 & 1 & \text { Renuncias de tutorías } \\ 1 & 2 & \text { Asignación de alimentos } \\ 18 & 1 & \text { Problemas de herencias y cuentas paternas (y concursos de acreedores) } \\ 7 & 1 & \text { Cobro de deudas y bienes de las herencias paternas } \\ 2 & 1 & \text { Apropiación (o entrega) de bienes por parte de los albaceas } \\ 3 & 1 & \text { Alcance de las cuentas de menores con sus tutores } \\ 4 & 1 & \text { Reclamación de dotes de menores } \\ 4 & 1 & \text { Cuestiones de mayorazgos, vínculos y capellanías } \\ - & 1 & \text { Criminalidad: daños, estupros, etc. } \\ 42 & - & \text { Otros }\end{array}$

en su nombre su curador, por acusarle de haberle golpeado en el vacío derecho cuando estaban celebrando con hogueras y baile el nombramiento de beneficiado de preste local»; ARChVa, Salas de lo Criminal, caja 384,3 (1795). 
MÁXIMO GARCÍA FERNÁNDEZ

TUTELA Y MINORÍA DE EDAD EN LA CASTILLA RURAL:

PRÁCTICAS COTIDIANAS DE ANTIGUO RÉGIMEN

Geografía provincial de los litigios por tutorías de menores

$\begin{array}{llllr} & \text { XVI (112) } & \text { XVII (48) } & \text { XVIII (19) } & \text { Total (179) } \\ \text { Capitales Provincia } & 3026,8 \% & 1122,9 \% & 422,2 \% & 45 \quad 25,1 \% \\ \text { Valladolid } & 19 & 5 & 2 & 26 \quad 14,5 \% \\ \text { Castilla y León } & & & & 120 \quad 67,0 \%\end{array}$

Geografía provincial de los litigios por curadurías de menores

\begin{tabular}{|c|c|c|c|c|c|c|}
\hline \multirow[b]{2}{*}{ Capitales Provincia } & \multirow{2}{*}{$\begin{array}{l}\text { XVI }(150) \\
4932,7 \%\end{array}$} & \multirow{2}{*}{$\begin{array}{l}\text { XVII (96) } \\
2020,8 \%\end{array}$} & \multicolumn{2}{|c|}{ XVIII (83) } & \multicolumn{2}{|c|}{ Total $(329 ; 33,6 \%$} \\
\hline & & & \multicolumn{2}{|c|}{$1315,7 \%$} & 82 & $24,9 \%$ \\
\hline Valladolid & 29 & 15 & \multicolumn{2}{|l|}{13} & 57 & $17,3 \%$ \\
\hline \multicolumn{5}{|l|}{ Castilla y León } & 217 & $66,0 \%$ \\
\hline \multicolumn{2}{|c|}{ Ámbito espacial de los conflictos (tutorías) } & XVI & XVII & XVIII & & Total \\
\hline \multicolumn{2}{|c|}{ Pleitos entre personas de la misma localidad } & 74 & 37 & 11 & & 122 \\
\hline \multicolumn{2}{|c|}{ Participan personajes de distintas localidades } & 38 & 11 & 8 & & 57 \\
\hline \multicolumn{2}{|c|}{$\%$ (de distintas localidades) } & $33,9 \%$ & $22,9 \%$ & $42,1 \%$ & & $31,8 \%$ \\
\hline \multicolumn{2}{|c|}{ Ámbito espacial de los conflictos (curadurías) } & XVI & XVII & XviII & & Total \\
\hline \multicolumn{2}{|c|}{ Pleitos entre personas de la misma localidad } & 104 & 70 & 57 & & 231 \\
\hline \multicolumn{2}{|c|}{ Participan personajes de distintas localidades } & 46 & 26 & 26 & & 98 \\
\hline \multicolumn{2}{|c|}{$\%$ (de distintas localidades) } & $30,7 \%$ & $27,2 \%$ & $31,3 \%$ & & $29,8 \%$ \\
\hline
\end{tabular}

Fuente: ARChVa. Pleitos Civiles.

Tabla 3. Catálogo de pleitos suscitados ente la Real Audiencia y Chancillería de Granada (siglos XVI-XVIII)

$\begin{array}{rrl}\text { XVI-XVII } & \text { XVIII } & \text { Causas de los litigios } \\ 8 & 9 & \text { Rendir cuentas administración del tiempo tutoría (restitución de bienes) } \\ 3 & 2 & \text { Doble: Posesión de tutela y Rendición cuentas y administración tutelas } \\ 4 & 3 & \text { Reclamación y reconocimiento de tutelas } \\ 3 & 1 & \text { Alimentos del menor } \\ 18 & 22 & \text { Problemas sobre herencias y cuentas paternas (y concursos acreedores) } \\ 5 & 3 & \text { Cobro de deudas y bienes de las herencias paternas } \\ 15 & 11 & \text { Pleitos entre hermanastros o vínculos por el reparto de tierras } \\ 1 & 4 & \text { Reclamación de dotes de menores } \\ - & 1 & \text { Bienes de monjas } \\ 4 & 2 & \text { Herencias de casas } \\ 6 & 3 & \text { Ejecución de bienes de menores (o pago bienes a menores) por censos } \\ 30 & 40 & \text { Mayorazgos, vínculos, capellanías, patronatos y fundaciones } \\ 7 & 3 & \text { Contra concejo-vecinos por apropiación bienes-rentas-cargos menores } \\ 2 & 2 & \text { Criminalidad: echar a la calle, lesiones, daños, estupros, etc. }\end{array}$

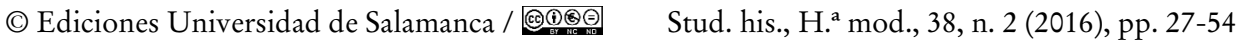


MÁXIMO GARCÍA FERNÁNDEZ

TUTELA Y MINORÍA DE EDAD EN LA CASTILLA RURAL: PRÁCTICAS COTIDIANAS DE ANTIGUO RÉGIMEN

Geografía provincial: los litigios por tutorías y curadurías de menores

$\begin{array}{llll} & \text { XVI }(41) & \text { XVII (75) } & \text { XVIII (113) } \\ \text { Capitales provinciales } & 1434,1 \% & 3040,0 \% & 3228,3 \% \\ \text { Granada } & 8 & 12 & 13 \\ \text { Córdoba } & 6 & 12 & 20\end{array}$

Total (229)

$7633,2 \%$

$3314,4 \%$

$3816,6 \%$

Andalucía

$158 \quad 69,0 \%$

Ámbito espacial de los conflictos

$\begin{array}{llll}\text { XVI } & \text { XVII } & \text { XVIII } & \text { Total } \\ 31 & 60 & 94 & 185 \\ 10 & 15 & 19 & 44 \\ 24,4 \% & 20,0 \% & 16,8 \% & 19,2 \%\end{array}$

Pleitos entre personas de la misma localidad

Participan personajes de distintos lugares

$\%$ (de distintas localidades)

$24,4 \% \quad 20,0 \%$

$19,2 \%$

Fuente: ARChGr. Pleitos Civiles.

Resulta muy significativo que, siendo muchos los casos promovidos por el propio tutor o curador en defensa de los legítimos intereses de los menores a su cargo (en Granada las demandas interpuestas por ellos sumaban el 58\%), en otro porcentaje igual de elevado y próximo también a la mitad de los pleitos en cuestión las reclamaciones provenían de la disconformidad del resto de la familia con el obrar de dichos personajes, solicitándoles rindiesen cuentas fidedignas de sus quehaceres, al sospecharse (o en la plena seguridad) de sus manifiestas y públicas malversaciones. Se entremezclaban, por lo tanto, muy buenas y nefastas representaciones en pro y en contra de una correcta protección o de la desintegración y dilapidación de las haciendas heredadas.

Dentro de esa realidad, las causas de los litigios eran enormemente variadas, aunque también aparecen significativamente concentradas en temáticas muy concretas. Identificada una treintena de fuentes conflictivas, una cuarta parte de ellas (una decena mejor dicho, si se unen la proliferación de 'problemas de herencias y cuentas paternas -y concursos de acreedores-', los 'pleitos entre hermanastros por el reparto de tierras' y las cuestiones por 'mayorazgos, vínculos, capellanías, patronatos y fundaciones' en el ámbito granadino) resultaron claves. Lo cierto fue que 'la rendición de cuentas por la administración del tiempo de la tutoría-con no pocas 'solicitudes de restituciones de bienes'- fue uno de los motores para aquella reiteración de la interposición de las querellas juveniles (más del 30\% de las conservadas en el tribunal de Valladolid). A lo que se unían los juicios 'entre tutores y curadores por una mala administración de las minorías de edad', la 'posesión, reclamación y reconocimiento de tutelas', las 'renuncias de tutorías' y las 'asignaciones alimenticias' o las dobles -o triples- interrelacionadas: 'reclamación de tutela y entrega de herencias (dadas indebidamente)' y 'posesiones de 
MÁXIMO GARCÍA FERNÁNDEZ

TUTELA Y MINORÍA DE EDAD EN LA CASTILLA RURAL:

PRÁCTICAS COTIDIANAS DE ANTIGUO RÉGIMEN

tutela y rendiciones de cuentas y administración de tutelas'. Mientras esas motivaciones, claramente económicas y materiales sumaban ya más de la mitad de las vallisoletanas, solo constituían un $14 \%$ al sur del Tajo, donde una tercera parte estaban ligadas a la vinculación de mayorazgos, con otro 17,5\% (frente al 10,6\%) a la transmisión hereditaria y hasta un $11,4 \%$ debidos a pugnas entre hermanos; y aumentando todos principios originarios, mientras al norte de dicho río iban disminuyendo progresivamente durante el transcurso de la Edad Moderna.

Una obligación de rendir cuentas para restituir ciertos bienes en conflicto a los menores discriminados frente a la defensa meridional de la concentración del terrazgo en unas pocas manos resume aquella amplísima casuística.

Además, únicamente un 25\% (un 33\% en Granada), y disminuyendo al desgranarse el Antiguo Régimen, se dilucidaban en los espacios urbanos de las capitales provinciales: el resto tenían como protagonistas a distintos tutores y menores de los ámbitos rurales castellanos. Y siempre más del 70\% (un 80\% al sur del Tajo) entre personas de una misma localidad y con intereses muy inmediatos en el control de cuentas y heredades. Los más próximos a los tribunales accedieron con mucha más frecuencia a las salas cancillerescas; así, vallisoletanos y granadinos, con cordobeses y salmantinos, sumaban un tercio de los encausados. Las dos terceras partes de los pleitos registraron como protagonistas a los castellanos y leoneses o a los andaluces. Los murcianos tampoco tuvieron inconveniente en desplazar a sus procuradores; lo mismo que riojanos, burgaleses o palentinos. Aunque igual de significativo sea de cara a mostrar lo arraigado de aquellas prácticas que cacereños, vizcaínos o madrileños registrasen unas tasas de asistencia litigante muy elevada.

Lo cierto fue que las cuestiones vinculadas a la tutoría de aquellos adolescentes no solo se relacionaban, ni mucho menos, con los pleitos dilucidados ante la justicia. Además de las Chancillerías, en paralelo, otros problemas e instituciones han legado otras posibilidades de acercamiento a la trascendencia del hecho de la minoría de edad y la juventud castellana. En ese sentido, mención especial merece el análisis de las escrituras protocolizadas relacionadas con este tema. No todo lo abundantes para este ámbito meseteño como pueda pensarse, ni tan variadas como en otras zonas castellanas periféricas, aun así permiten plantear interesantes cuestiones de debate; y no tanto vinculadas en exclusiva con la curaduría testamentaria, donde ya se advierte que los patrones extremeño, gallego, zamorano o vallisoletano ilustran sobradamente aquella realidad postrera de confianzas, preocupaciones y protecciones juveniles, como respecto a las propias contabilidades periódicas presentadas por los tutores.

Cuatro casos locales perfilan este extremo. En las vallisoletanas Rueda, Portillo, Pozaldez o Alcazaren de todas las minutas recogidas por los escribanos en sus concejos en el último cuarto del siglo XviII, únicamente se registraron una treintena 
MÁXIMO GARCÍA FERNÁNDEZ

TUTELA Y MINORÍA DE EDAD EN LA CASTILLA RURAL: PRÁCTICAS COTIDIANAS DE ANTIGUO RÉGIMEN

de escrituras de tutorías y curadurías, y solo relativas a la confirmación de la nominación testamentaria ${ }^{18}$. Más abundantes en los años noventa, 'emancipaciones de menores' o 'habilitación para el régimen de gobierno y bienes' y presencia a la vez de varios hermanos, definen aquellos mandatos. Es decir, no muy numerosas y ninguna dativa, ni haciéndose cargo el común de los huérfanos no protegidos por última voluntad. Y respecto a la cuestión capital de la administración tutorial de la vivencia cotidiana de aquellos menores apenas se han encontrado hasta el momento otra cincuentena de ejemplos (hasta mediados del xIx) ${ }^{19}$.

TABla 4. Cuentas de tutoría escrituradas en varias localidades rurales de la provincia de Valladolid 1706-1850

$\begin{array}{cccccc}1706-1718 & 1746-1761 & \text { siglo xix } & \text { Total } & \text { Mayorga } & \text { Nava Rey, Tudela y Portillo } \\ 6 & 25 & 21 & 52 & 26 & 26 \\ 11,5 \% & 48,1 \% & 40,4 \% & & 50,0 \% & \end{array}$

Fuente: AHPVa. Protocolos Notariales.

Presentaban recibos detallados, memoriales pormenorizados de cuentas, gastos de ropa, calzado y boticas, abarcando hasta catorce años de minoría de edad. Más abundantes a medida que se acercaba el fin del Antiguo Régimen $y$, fundamentalmente, en la villa terracampina de Mayorga de Campos ya a medidos del siglo xviII.

Aún sin aclarar los consumos de aquellos menores, la asiduidad tutorial en el mundo rural castellano fue una práctica cotidiana cada vez más frecuente ${ }^{20}$. ¿Cómo repartir con justicia unos escasos enseres muebles sin perjudicar a ningún menor $?^{21}$ En la 'partición de la hacienda de Andrés Crespo' «dejó por herederos a

18. AHPVa, Secc. Prot., leg. 14058 (1). Índice de Escrituras Protocolizadas, por testimonio de Toribio García, escribano del concejo de Pozaldez (1770-1819); AHPVa, Secc. Prot., leg. 8368. Ante Antonio Callejo, notario del concejo de Rueda (1766-1829); AHPVa, Secc. Prot., leg. 14058 ( 2 y 5). Por testimonio de Manuel Benito, escribano del número y del ayuntamiento de Portillo (1780-1810); AHPVa, Secc. Prot., leg. 14058 (14 y 16). Por testimonio de Rafael García, escribano del número y del ayuntamiento de Alcazarén (1790-1849).

19. Por ejemplo: Nava del Rey, leg. 13587 (1713); o Mayorga de Campos, leg. 12851 (1751$1753)$.

20. García Fernández, M.: «Tutorías y cuentas de gastos de menores: consumos juveniles diferenciados en la Castilla del Antiguo Régimen», en Muñoz Navarro, D. (Ed.): Comprar, vender y consumir. Nuevas aportaciones a la historia del consumo en la España moderna. Valencia, 2011, pp. 123-152.

21. ARChVa, Pleitos Civiles. Pérez Alonso, olvidados, caja 23.3 (Bocigas, 16 de noviembre de 1707); o AHPVa, Secc. Prot., leg. 11307, fol. 539-562 (Bocigas, 1730). 
MÁXIMO GARCÍA FERNÁNDEZ

TUTELA Y MINORÍA DE EDAD EN LA CASTILLA RURAL:

PRÁCTICAS COTIDIANAS DE ANTIGUO RÉGIMEN

sus tres hijos, Catalina, Gertrudis y Esteban, inhábiles para administrar su patrimonio. Para que en todo tiempo constasen y no hubiese ocultación de los que son y los acreedores que hubiere, se ordena hacer cuenta y razón de los bienes que a dichos menores convienen. Tras su inventario solemne se depositen en persona abonada. Para ello, el señor José Zurro, alcalde ordinario de Ciguñuela, nombró por curador ad litem de los susodichos a Tomás Crespo, de esta vecindad, a quien se le notifique lo acepte, jure y afiance, apremiándole para que se le discierna tal cargo. Él, mediante la utilidad y beneficio que se sigue a los pupilos, desde luego consintió que por los contadores nombrados se le pase a hacer tal adjudicación. Presente Ambrosia Fraile, su viuda y su madre». 'Han de haber' los tres, y en su nombre Tomás, 615,5 reales, a 205 cada uno ${ }^{22}$.

Así, en amplias zonas rurales, entre 1610 y 1810, las actuaciones judiciales por deudas relacionadas con las curadurías eran ciertamente importantes y mantenidas a lo largo del tiempo; las que tenían su origen en 'cuestiones sucesorias' alcanzaron su máximo hacia 1710-30 (medio siglo después en otros alfoces). Entre las razones sobresalientes: la propia partición de los bienes, seguida de la ocupación indebida de los indivisos, las disputas por dotes femeninas o en función de donaciones intervivos y vinculaciones. Todos aquellos motivos apuntaban tensiones dentro de la familia campesina ${ }^{23}$.

Pleitos por muy poco; tutores y curadores de casi nada; menores supervivientes.

En cualquier época y lugar más o menos poblado ${ }^{24}$.

\section{El mantenimiento de los menores en la Castilla Moderna}

Aunque no suelen encontrarse cuadernos de contabilidad del gasto doméstico popular que permitan analizar la microeconomía rural y su consumo en vestuario, calzado, ostentación, alimentación, educación, alquileres, transporte, sanitario o en servidumbre, la gestión de bienes por parte de los tutores puede refrendar aquellas 'economías juveniles' como parte de la historia de la vida material cotidiana.

El 'padre de menores' debía asentar las 'cuentas de la tutela', incorporándose su asiento a las escribanías del concejo (al igual que las registradas por los tutores

22. AHPVa, Secc. Prot., leg. 14070 (12), fol. 1 y ss. (Ciguñuela, 1766).

23. Mantecón Movellán, T. A.: Conflictividad y disciplinamiento social en la Cantabria rural del Antiguo Régimen. Santander, 1997, pp. 198-206.

24. Véase: Herrero Jiménez, M.: Padrones y registros notariales medievales abulenses en el Archivo de la Real Chancillería de Valladolid. Ávila, 2010, pp. 263 y 294. 
MÁXIMO GARCÍA FERNÁNDEZ

TUTELA Y MINORÍA DE EDAD EN LA CASTILLA RURAL: PRÁCTICAS COTIDIANAS DE ANTIGUO RÉGIMEN

testamentarios). Sin embargo, los fondos archivísticos municipales vallisoletanos no conservan documentación de interés sobre estas 'tutelas dativas' ${ }^{25}$.

En cualquier caso, tanto en zonas rurales como urbanas, en aquellos momentos vinculados a vivencias fúnebres en la casa en la que habitaban aquellos menores, no pocos tutores tuvieron la necesidad de poner en venta la poca hacienda raíz heredada o llamar al pregonero para la pública almoneda de sus escasos bienes muebles tasados. No obstante, la gestión de sus patrimonios nos es en gran medida desconocida: muchas testamentarías no los explicitan y no siempre se cumplían las contabilidades o la presentación periódica de cuentas oficiales, aparte de otras consideraciones que trataban de minimizar el papeleo, tendentes a evitar intromisiones extrañas y a eximir a los huérfanos de costes administrativos. Aun así, algo cabe deducir de los recursos de financiación destinados al cuidado de los menores y de las prácticas de gestión orientadas a preservar las herencias recibidas, así como sobre la constatación de las principales necesidades vinculadas a su crianza. Nos interesa más el segundo aspecto.

Según los presupuestos contables extremeños conservados, deudas paternas, cumplimientos testamentarios y no pocos pleitos consumían la mayor parte de aquellos patrimonios. Junto a esos gastos (casi las cuatro quintas partes de los desembolsos ejecutados), solo los derivados de los costes de la manutención de los menores eran relevantes. Por contraste, las atenciones a la cobertura de las necesidades personales de vestido o educación eran mínimas ${ }^{26}$.

¿La vida juvenil se caracterizaba por una suficiente alimentación y diversidad de vestuario? Los memoriales de cuentas de tutoría rurales andaluces destacan las pocas posibilidades de aumentar sus demandas ${ }^{27}$. Los excedentes agropecuarios, aunque su poder adquisitivo fuese elevado, no se dirigían a adquirir bienes de lujo, ni a satisfacer ambiciones sociales, ni a altos niveles de consumo suntuario y de ostentación.

Aunque su contenido sea muy heterogéneo, aquellas memorias económicas ('cuentas de menores') presentan un alto grado de fiabilidad contable. Simplificándose a lo largo del tiempo, todas seguían una misma estructura: cargo y

25. Cava López, M. ${ }^{a}$ G.: «Economías infantiles: recursos materiales y gestión del patrimonio de los huérfanos extremeños durante la Edad Moderna», Obradoiro, 8, 1999, pp. 91-97 ('La gestión patrimonial', pp. 85-98). Véase Merchán Álvarez, A.: La tutela de los menores en Castilla hasta fines del siglo XV. Sevilla, 1976, pp. 75 y 166.

26. Cava López, M. ${ }^{a}$ G.: «Economías...», art. cit., ‘Gastos’, pp. 89-91.

27. NúÑEz Roldán, F.: «Fuentes y metodología para el estudio de la infancia rural: las tutelas y las cuentas de menores en los siglos XVI y XVII», en NúÑEz Roldán, F. (Ed.): La infancia en España y Portugal. Siglos XVI-XIX. Madrid, 2011, pp. 133-148. 
MÁXIMO GARCÍA FERNÁNDEZ

TUTELA Y MINORÍA DE EDAD EN LA CASTILLA RURAL: PRÁCTICAS COTIDIANAS DE ANTIGUO RÉGIMEN

descargo con sus alcances, sobre la base del inventario de bienes paterno hecho al encargarse de la tutoría, y cuyo proceso concluiría al finalizar su minoría de edad, aunque también fuese común hallar al tutor presentándolas anual, bianualmente o incluso por períodos de tiempo más largos. Certificadas las diferentes partidas contables, el capítulo de los gastos personales domésticos informa sobre la alimentación de los huérfanos, su estado de salud, los esfuerzos de dichos pupilos por educarse (en buenas maneras, aprendiendo a escribir, leer y contar o como aprendiz ejercitado en un oficio) y con su vestuario, 'hechura de ropa' y calzado.

Cuando el monto de lo que el tutor consideraba 'menudencias' (y eso que algún año sumaban casi la mitad de los desembolsos) ajenas a la explotación de la hacienda raíz encomendada ascendía, entonces el gasto en alimentación era mayor, mientras que los conceptos textil y calzado se reducían al mínimo. En cambio, al disminuir porcentualmente el conjunto de lo 'menudos' era el consumo en vestuario el que más crecía, hasta sobrepasar un importante 14\%-17\% (un 20\% máximo). Al ser una demanda elástica para los menores, su peso solo aumentaba tras cubrirse otras necesidades juveniles básicas: el montante para aquellas familias propietarias en satisfacer sus exigencias domésticas y de prestigio era menos importante cualitativa y socialmente que sus costes agropecuarios ${ }^{28}$.

Por su parte, apenas las encontramos detalladas a orillas del Duero. Aun así, las 138 cuentas de la administración y gasto de los bienes de menores del lugar de Barromán, jurisdicción de Arévalo, tomadas por el 'padre de menores' en presencia de los fieles de fechos del lugar entre 1565 y 1627 reflejan ya no pocos significados trascendentes para comprender la evolución del consumo y las demandas juveniles ${ }^{29}$.

Con situaciones muy dispares, donde también cabían estudios y boticas ${ }^{30} ; \mathrm{y}$ cuando los alcances finales eran tanto favorables a los menores como a los tutores.

Menores que pasaron no pocos años de sus jóvenes vidas en casas ajenas.

28. Ibidem.

29. ARChVa, Protocolos y Padrones, caja 24,1.

30. Ibidem. Siendo 'padre de menores' Pedro Serrano, en 1617, Francisca Martínez fue curadora del menor Antonio Gutiérrez. En el descargo de 99.497 maravedíes es sintomático que las partidas pormenorizadas con mayor detalle fuesen los «pagos al maestro que enseñó a leer y a escribir tres temporadas al menor 54 reales (1.836 maravedíes, producto de tres fanegas de trigo), más otros 48 reales (1.632 mrs.) de los seis meses, pagando cada mes a dos reales de leer y escribir y uno y medio de leer y cuatro reales de papel; más al preceptor de gramática, $1.700 \mathrm{mrs}$.». Si la 'escuela' importaba $5.168 \mathrm{mrs}$. (un 5,2\%), los «zapatos, calzas y sombreros, y camisas y vestidos» sumaban $5.669 \mathrm{mrs}$. $(5,7 \%)$, mientras que la «botica y barbero» otros $1.151 \mathrm{mrs} .(1,2 \%)$. Al final, se debían casi cinco mil maravedíes a Francisca. 
MÁXIMO GARCÍA FERNÁNDEZ

TUTELA Y MINORÍA DE EDAD EN LA CASTILLA RURAL: PRÁCTICAS COTIDIANAS DE ANTIGUO RÉGIMEN

Tabla 5. Duración de los pleitos por tutorías y curadurías (porcentajes)

$\begin{array}{lrr}\text { Entre } 7 \text { meses }-1 \text { año } & 4,4 & 22,2 \\ \text { Entre } 2 \text { años }-9 \text { años } & 56,4 & 33,3 \\ \text { Entre } 10-12 \text { años } & 26,1 & 22,2 \\ \text { Entre } 14-19 \text { años } & 13,0 & 22,2\end{array}$

Fuente: ARChVa. Pleitos Civiles.

Breves estancias o tan amplias que se acercaban al máximo legal posible, lo que siempre repercutiría en desarraigos o situaciones frecuentes de inestabilidad parentelar.

Aunque solo un 10\% de los casos ofrece información detallada y pormenorizada sobre el gasto en el consumo anual, y con cargos muy variados (tan dispares que fluctuaban entre los 400.000 y los 7.000 maravedíes) cabe deducir que el desembolso en alimento (constituía únicamente un 5,9\% medio, pero alcanzando hasta el $24,2 \%$; en otros casos un $18,5 \%$ o un $17 \%$, frente a un $8,6 \%$ y el $3,7 \%$ mínimo) era muy superior al empleado en la ropa de vestir de los menores. El vestido suponía entre un $1 \%$ y el $52 \%$ de los descargos: un reducido $4,9 \%$ por término medio (aunque enormemente variable también: otros, un $49,1 \%$, el $37,5 \%$ o un $10 \%$, bajando hasta el $3 \%)^{31}$.

31. Ibidem. En 1605, en el descargo general de la menor María Martín (6.568 maravedíes; el 38\% del cargo) destacaban: unas tocas, 204 mrs.; dos varas de estopa para el cuerpo de una camisa, 100 mrs.; unos zapatos doblados «que compró a la menor», 136 mrs.; zapatos, calzas e hilo "para una camisa que le dio», 285 mrs.; cinco varas de pardillo, 1.530 mrs.; hechura de dos sayas, 204 mrs.; paño para los cuerpos, 1.564 mrs.; su hechura, 51 mrs.; picadillo para un sayuelo, 374 mrs.; hechura de un capirote, 44 mrs.; tocado y mantilla, 255 mrs.; de paño pardo para unas calzas, $357 \mathrm{mrs}$.; dos tocados «que la compró», $234 \mathrm{mrs}$.; hechura de un sayuelo de picadillo, 58 mrs.; hechura de una saya, 60 mrs.; hechura de dos camisas, 68 mrs.; aderezo de zapatos, 58 mrs.; hechura de calzas, 102 mrs.; de los ruedos de las sayas, 204 mrs.; una mantellina negra de veintidoseno, 544 mrs.; y una mantilla, 136 mrs.; Solo 1.785 maravedíes, pero el 49,1\% del gasto, empleó en 1608, Blas Conde, su curador, en el avituallamiento del menor Francisco Velázquez. En concreto: cinco varas de paño "para hacerle de vestir al menor», 935 mrs.; una camisa de lienzo «que se le hizo», 204 mrs.; "costó un cuello para su menor», 170 mrs.; del hilo para el cuello, 34 mrs.; unos zapatos que compró, 102 mrs.; un sombrero, 68 mrs.; y la hechura de un vestido, 272 mrs. En 1600, el alcance contra el tutor de Catalina López (aún se lo debía a la menor) se fijaba en 228.791 maravedíes. En el descargo (20.023,5 mrs.), un 10\% estaba formado por una saya, 748 mrs.; tres camisas de lienzo, 816 mrs.; un capirote, 204 mrs.; cuatro pares de zapatos, 137 mrs.; y unas calzas que apenas costaron 85 mrs. Finalmente, en 1627, el menor Pedro de Vallejo recibió de su curador Diego Muñoz: cuatro varas y media de paño «para hacer de vestir al menor», 1.343 maravedíes; hechura, con su hilo y botones, 
MÁXIMO GARCÍA FERNÁNDEZ

TUTELA Y MINORÍA DE EDAD EN LA CASTILLA RURAL: PRÁCTICAS COTIDIANAS DE ANTIGUO RÉGIMEN

En resumen: no solían faltar unos imprescindibles jubones, de mejor o peor calidad, junto a un par de zapatos. También se reiteraban ciertos «pagos al sastre por la costura», además de la adquisición de paños, hilo, botones y agujas necesarios. La hechura (o el aderezo) de sayas, camisas, calzas y capirotes tampoco se descuidaba, pero eran menos frecuentes las menciones de sombreros, calzones y cuellos.

\section{TUTORÍAS Y CONSUMOS: CULTURA MATERIAL POPULAR RURAL}

Sobre pagos tutoriales de deudas en medicinas, liquidación general de cuentas o su nulidad, «años que sirvió como criada», educación de nietos y sobrinas, abono de alimentos y gastos de manutención, salarios «del tiempo de servicio» invertido en tales tutorías (desde siete meses a 19 años), entrega de dotes, alquileres de casas, presencia de madres curadoras vueltas a casar, disputas entre hermanos, repartos hereditarios, abusos del cargo, desaparición y desfalcos patrimoniales, algún vestuario y zapatería, la defensa legal ante acusaciones criminales (en general a partir de la documentación sobre pleitos civiles conservados),... en torno a las «crianzas de una criatura» y para utilidad de aquellos pupilos menores, se cuenta ya con información de interés sobre las que establecer algunas reflexiones de alcance.

Como hemos indicado anteriormente, aunque a finales del Antiguo Régimen se requerirían cada vez con mayor frecuencia, ya en el entorno campesino castellano del entorno del Duero del siglo xvi las tutorías eran una realidad asidua. De los gastos de los tutores testamentarios (tras la entrega entonces de las obligadas 'cuentas de curaduría de menores' al finalizar sus funciones), empezamos a vislumbrar la vestimenta juvenil masculina y buena parte del consumo familiar de nuevos ropajes.

Sabido es que el consumo de ropa de vestir (y la compra de tejidos en pieza para su posterior confección) siempre fue muy elástico, pero ahora nos acercamos, además, a la tasación de su hechura, con lo que la sastrería (y las costureras) cobran una nueva dimensión. Y estas cuentas de tutoría también informan del recambio más o menos permanente de calzado existente entonces, y del que apenas contábamos con noticias en las dotes femeninas y ni siquiera en los más completos inventarios post-mortem.

de un jubón de lienzo y aderezo de capotillos y valonas, 612 mrs.; de zapatos y sombreros, 204 mrs.; lienzo y estopa para hacer un jubón, 280 mrs.; «menudencias de paño, lienzo y estopa», 1.078 mrs.; otras cuatro varas y media de paño, 1.606 mrs.; la hechura de un jubón, 442 mrs.; unas calzas, 136 mrs.; y unos zapatos y un sombrero, 323 mrs. En total: 9.024 maravedíes, un $51,8 \%$ de aquella data. 
MÁXIMO GARCÍA FERNÁNDEZ

TUTELA Y MINORÍA DE EDAD EN LA CASTILLA RURAL: PRÁCTICAS COTIDIANAS DE ANTIGUO RÉGIMEN

Una niña -como la menor vallisoletana Ana de Espinosa- rompía hasta seis pares anualmente. Lo interesante es llegar a saber si constituía una práctica habitual. Algunos varones podían gastar más y hasta el doble: como los doce "que rasgó el dicho año» Juan de Pesquera (aunque su hermano, también vecino de Valladolid, solo estropease dos). Adquisición de zapatos nuevos, del mismo modo que el «arreglar unas botas» provocaba el recurso frecuente a los zapateros remendones y de viejo. Renovaciones, relacionadas posiblemente con su escasa calidad, que reflejan además un ritmo de reposición más activo de lo que siempre se ha pensado y mucho más consumista que la del más duradero vestuario pañero.

Aun así, para buena parte de aquella sociedad castellana tradicional, el dinero invertido en el recambio permanente de prendas de vestir no era prioritario, ni siquiera en las etapas juveniles cuando la propensión al consumo debería ser más acusada. Únicamente los aportes dotales en el momento matrimonial y la realización de algún viaje de estudios o clerical permitían incrementar el desembolso -en todo caso puntual- en enseres novedosos para la satisfacción de sus necesidades.

Entre las prendas adquiridas para dichos menores aparecían siempre las más típicas. Y resulta muy interesante que todos recibieron bastante calzado: seis pares de zapatos cada año, durante cuatro, gastó uno de ellos. Más «dos camisas anualmente». En fechas señaladas: por Navidad y en otras festividades locales. Aquellos jóvenes de procedencia rural, algunos «de pupilaje y puestos a la escuela», eran fiel reflejo de que la difusión y el recambio textil no estaba tan limitado como reflejan otras fuentes sobre la cultura material castellana ${ }^{32}$.

El balance ofrecido por Pascual de Pesquera, hortelano de Valladolid, de la minoría de edad de Tomé de Pesquera, incluía una relación de todos los gastos efectuados durante los cuatro años y medio de su tutoría ${ }^{33}$.

Su vestuario solo constituía un modesto $18,1 \%$; muy por detrás de su sustento cotidiano (nada menos que el $41,2 \%$ ). Incluso sus pagos por motivos formativos eran relevantes (otro 4,8\%). Adquisiciones de su atuendo con una relativa regularidad temporal a lo largo de todo el periodo, aunque más concentradas, tanto

32. García Fernández, M.: «Tutorías...», en Muñoz Navarro, D.: op. cit., pp. 139-145.

33. AHPVa, Secc. Prot., leg. 49, fol. 377. Unas calzas pardas (se las compró en octubre), 221 maravedíes; dos camisas (ese mismo octubre), 272 mrs.; una capa y un sayo negro (comprados la víspera de Navidad), 1.360 mrs.; y unas botas y un sombrero (la víspera de Pascua de Flores del año siguiente), 162 mrs.; Un sayo (comprado en esas mismas pascuas, «porque le hurtaron el otro»), 680 maravedíes; unos zaragüelles (en mayo), 65 mrs.; una camisa (en agosto), 119 mrs.; un jubón, calzas y agujetas (en octubre), 289 mrs.; y unas medias calzas y unos zaragüelles (para las navidades), 153 mrs.; unas calzas (adquiridas en enero dos años después), 442 maravedíes; unas calzas, zaragüelles y un jubón («que le di en junio»), 408 mrs.; y una ropa (comprada también en junio), 136 mrs. 
MÁXIMO GARCÍA FERNÁNDEZ

TUTELA Y MINORÍA DE EDAD EN LA CASTILLA RURAL: PRÁCTICAS COTIDIANAS DE ANTIGUO RÉGIMEN

en cantidad como en calidades, en los dos primeros años de la actuación tutorial (en momentos festivos como las vísperas de Navidad o por Pascua de Flores, pero distribuido dicho gasto con una cierta cadencia mensual). Aquella treintena de piezas surtieron la imprescindible camisería, calcetería, jubonería y sombrerería (con una cuarta parte del desembolso correspondiente al calzado). Se trataba de atavíos recién comprados, pero también del 'aderezo' de cueras y sayos viejos. Por necesidades de recambio y uso, o por hurtos. Su imagen era la de cualquier otro estudiante manteísta de la época: jubón (sobre la camisa), zaragüelles y medias calzas atacadas.

La cuenta de tutoría y curaduría dada por el mismo Pascual, ahora de la minoría de edad de Juan de Pesquera, hermano del anterior, pero clérigo rural, en el mismo año de 1553, presenta rasgos similares junto a otras interesantes diferencias y cuestiones vitales relevantes. Un punto que interesaría resaltar y dilucidar (aunque no podamos resolver todavía) es si tales contrastes se relacionan con la propia voluntad de demanda de cada menor o si el influjo crucial del tutor en dicho comportamiento económico-cultural consumista era el determinante.

Esta minuta duplicaba la precedente: en cantidades y conceptos, dos hermanos consumían de forma muy diferente. Ni la educación sacerdotal, ni su alojamiento y pupilaje, generaron dispendios reseñables. Su alimentación fue bastante mejor: durante otros cinco años, costó más que doblado, sobrepasando ya la mitad del total abonado por su tío. Lo desembolsado en vestido ahora también era más del doble que lo invertido en Tomé, aunque debido a la calidad de las prendas y no a su número, que era similar, alcanzando ya la cuarta parte de su gasto juvenil.

En concreto, su vestuario (seis calzas, cuatro sayos y dos jubones, como piezas fundamentales) respondía a las mismas exigencias del porte común popular de la época. Con una cierta renovación anual, aunque concentrándose mucho aquella adquisición de prendas en pocos meses (cuando se compraron un caro manteo en enero, un bonete la víspera de Pascua de Flores, un jubón y unas calzas en abril y un buen sayo en mayo). Vestidos que supusieron más del $56 \%$ de sus desembolsos; lo que unido a su amplio surtido de camisería y a las hechuras (forros, botones, confecciones y aderezos), solo dejaban para calzado el $17 \%$ restante (menos que su hermano, aunque este capítulo de su consumo líquido realmente ascendiese hasta los 612 maravedíes al año).

Otros casos también ilustran aquella misma realidad.

Contamos con los ejemplos urbanos de las cuentas de dos años de curaduría de los menores privilegiados don Antonio y doña Catalina de Baeza ${ }^{34}$. Uno pícaro y

34. AHPVa, Secc. Prot., leg. 170, f. 3266; y leg. 164, fol. 166 y 637. 
juerguista (siempre pidiendo unos cuartos a su tutor «para una necesidad» gastados en caballos, viajes, naipes y queridas en Tudela, Tordesillas o Salamanca: «26 reales para unas calzas de aguja de lana negra, porque otros 26 que le di para ellas en abril, gastolos en chucherías, según dijo ¡yo creo que los jugó!»), frente a una dama mucho más recatada. Ambos con sus maestros especializados: de espada y guitarra para uno, de labores y danza para la otra. Ninguno escatimó (tampoco en refrescos y participación en rifas de guantes, bolsas y librillos) en sus vestuarios: rasos, sedas y terciopelos, en azul, blanco y verde. Ella (invirtiendo más del $50 \%$ de su asignación) con preferencia por los tonos morados, pero con adornos dorados y amarillos, perillas de ámbar, agnus deis guarnecidos en oro y varias sortijas de diamantes, más el menjuí para su tocador. Inversiones más lúdicas en uno frente a otras más de lucimiento externo; todas ellas de demostración pública de sus posibles.

Y en el rural burgalés Belorado, Nicolás Ruiz, tío de dos hermanos menores, Pedro y María Heredia, en la cuenta por inventario que presentó del tiempo que fue administrador de sus haciendas, insertaba la memoria de los bienes paternos recogidos en diciembre al finalizar su trabajo ${ }^{35}$. De ella se deducía que los cinco herederos solo recibieron en ropa y mobiliario doméstico unos pocos 34.771 maravedíes (apenas un 10,6\% del patrimonio familiar). De aquellas 145 piezas, diez eran «viejas, andadas y podridas» y cinco nuevas («una capa de refino buena, con su faja de seda, 9.625 mrs.» y «un capote negro de refino, $4.125 \mathrm{mrs} . »)$, junto a un amplio surtido de materias primas de confección muy comunes entonces en las casas de los sastres: lienzos y estopa.

Aunque sin anualidades pormenorizadas, también en un pequeño lugar de la Tierra de Pinares vallisoletana como lo era Bocigas, se archivaba, en 1619, una «cuenta de Antonio Martín Cubero [tío del menor] de lo gastado con Juan Sarmiento en nombre de Alonso Gómez [también vecino y curador de Juan]». Incluyendo muchos viajes desde su pueblo natal a bastantes de las principales ciudades castellanas, no fue corto el desembolso total efectuado (34.340 maravedíes), y eso que los pagos alimenticios diarios tampoco fueron demasiado copiosos durante aquellos nueve meses de estudio (no exentos de frecuentes momentos festivos). Así, a partes iguales, vestuario, comida y desplazamiento compusieron la data juvenil de aquel privilegiado tonsurado de menores. Un vestido de buen paño de diecinueve ducados fue el gasto más importante de todos los efectuados

35. ARChVa, Pleitos Civiles. Pérez Alonso, fenecidos, caja 1038.3 (1573-1574). 
MÁXIMO GARCÍA FERNÁNDEZ

TUTELA Y MINORÍA DE EDAD EN LA CASTILLA RURAL:

PRÁCTICAS COTIDIANAS DE ANTIGUO RÉGIMEN

(junto a la imprescindible sotana) para completar el consumo popular de aquel joven, en este caso bien atendido por su tutor ${ }^{36}$.

Y en pro de sus intereses, se condenaba (en Trebejo, Cáceres, allá por 1633) a Juana Martín, viuda del tutor Juan Gorrón, quien pleitearía maliciosamente a favor de la menor, Juana Estévez Gorrón, «en el valor de diez o doce años de agravios en los frutos de dicha hacienda, a razón de veinte ducados al año». De aquellos 220 reales, doscientos eran el resultado del gasto anual en alimentos (ducado y medio mensual) y únicamente veinte generados por las compras de su vestuario (9\%): un peso trascendental de los primeros frente al escaso consumo detectado en bienes semiduraderos ${ }^{37}$.

Por eso, sobre ese capítulo alimenticio los datos son más sabrosos. Constituía la principal partida del gasto de las tutorías, aunque las mensualidades invertidas en dar de comer a aquellos menores fuesen muy variadas. Desde ducado y medio al mes, pasando por tres, tres y medio y hasta los diecisiete (satisfechos para la privilegiada doña Antonia de Vozmediano en los agravios de las cuentas de su curaduría de 1612 a 1622) ${ }^{38}$. Rondaban aquellas minutas nutricionales el ducado mensual; es decir, un real, real y cuartillo diario o a real y medio por persona y día.

Durante el Setecientos las informaciones son más explícitas.

En 1715, el monto certificado en la memoria de lo que tiene suplido Francisco Antonio de Ustáriz, vecino de Santisteban, Navarra, con Antonio Miguel de Vancitart, en el tiempo que lo tuvo en su casa por un año, ascendía a sesenta ducados ${ }^{39}$. No parecen excesivos; y, sin embargo, a los tres ducados y medio de plata doble al mes -«a 42 por año»- gastados en su alimento y los cuatro del «salario de la escuela, papel, libros y plumas» debían sumarse nada menos que otros catorce del «vestuario exterior, camisas y calzado» comprados para el «decente atuendo» del joven Antonio Miguel. Anualmente, lo invertido en los tejidos y hechuras de sus ropas de vestir y zapatería representaba ya el 23,3\%.

También en el primer decenio del siglo xviI la tutoría de la menor Josefa de la Plaza es muy significativa. Su curador, Gaspar de Villelga (vecino leonés de Sahagún) se sentía tan agraviado porque no se habían aceptado los alcances proporcionados al final de sus gestiones que en el pleito que interpuso ofrecía un completo memorial explicativo de sus quehaceres. Las cuentas corroboraron un cargo de 209.966 maravedíes frente a una data de 187.547 mrs., alcanzado Gaspar en 22.419 mrs.,

36. AHPVa, Secc. Prot., leg. 10367 (2), fol. 40 y ss.

37. ARChVa, Pleitos Civiles. Fernando Alonso, fenecidos, caja 1988.1 (1633-1636 y 1656).

38. ARChVa, Pleitos Civiles. Alonso Rodríguez, olvidados, caja 199.8.

39. Idem, caja 660.4 . 
«que debe a su menor»..., toda vez que en los años precedentes, ni en alimentos ni en ropa, parece que lo proporcionado a la vida material de aquella joven fuese precisamente un buen trato. En primer lugar, traía a colación la hacienda recibida por la joven Josefa tras la muerte de sus padres en plena Tierra de Campos. La suma de sus ropas heredadas apenas llegaba a los $4.828 \mathrm{mrs}$. (un $3 \%$ ). En una cuenta inicial, la compra de unos zapatos suponía ya el doble (4,5 reales) que la adquisición de «beatilla para un capillo». Tres partidas componían el total de otra serie de desembolsos textiles efectuados (y que un testigo aseguraba ser ciertos, «lo sé porque lo vi pagar en Sahagún el sábado 15 de marzo»). El vestuario mercado entonces importó 37 reales: «tres pares de calzones» más la «hechura de dos camisas que se le han hecho». Prendas femeninas muy comunes y de todo uso entonces. El tercer capítulo resultó determinante entonces: «unos zapatos que la compré, seis», otros «zapatos que la muchacha llevó en los pies, siete» $\mathrm{y}$ «dos pares de albarcas, dos». El calzado conformaba nada menos que el 40,5\%, cuando otras fuentes ni siquiera mencionan la regularidad de su consumo... y rápido deterioro. Además, se confirmaban otros pagos en varios años consecutivos para la imprescindible vestimenta de la pequeña. «Costas de las hechuras de los vestidos [nuevos] que su tío Francisco Matías la sacó durante estas cuentas, 3.553 maravedíes», «se la compró para vestirse en especie de mercaderías, $3.400 \mathrm{mrs}$.» $\mathrm{O}$ «un poco de estameña prensada y otra pequeña cantidad de lienzo dado para vestir a dicha menor, $3.298 \mathrm{mrs} .{ }^{40}$. $\mathrm{Su}$ arca necesitaba bastante equipamiento; era lo más perentorio... pero excusable.

En muchos de aquellos conflictos las sentencias fueron favorables a los jóvenes, tratándose en todos los casos de tutorías instituidas en ámbitos rurales, por lo que su valor representativo se incrementa a la hora de comprender las pautas de relación con el mercado establecidas por buena parte del campesinado cuando se vinculaba con ambientes diferentes a los de origen y dónde lucir la persona y asemejarse a los modelos de la convivencia y la apariencia urbana era determinante.

Nuevas cuentas de tutoría que contengan memoriales y recibos detallados en gastos de vestimenta y calzado (y sobre sombrerería, capas o camisería) permitirán conocer mejor aquellos ritmos consumistas juveniles ${ }^{41}$. $\mathrm{O}$, cuando la tienda estable rural era inexistente y menos frecuentes aún los patrones y diseños exclusiva-

40. ARChVa, Pleitos Civiles. Alonso Rodríguez, fenecidos, caja 3136.2 (1701-1707). Más «los alimentos de todo el año pasado de 1699 y 51 días del antecedente (que el resto del año alimentó a Josefa, Gregorio de Rivas); a 24 maravedíes diarios en 1698 y a 34 mrs. en 1699, en total 13.600 mrs.».

41. Cava López, M. ${ }^{a}$ G.: «Niños e infancia en la investigación sobre la Edad Moderna: el abandono de una historia de abandonos», en Alvar Ezquerro, A., et al. (Eds.): Política y cultura en la época Moderna. Alcalá de Henares, 2004, pp. 751-761. 
MÁXIMO GARCÍA FERNÁNDEZ

TUTELA Y MINORÍA DE EDAD EN LA CASTILLA RURAL: PRÁCTICAS COTIDIANAS DE ANTIGUO RÉGIMEN

mente juveniles, continuando las investigaciones sobre el hecho de que muchas almonedas se realizaban cuando quedaban hijos menores de edad: los curadores fueron quienes procedieron a efectuar entonces dichas subastas al objeto de evitar el deterioro mobiliario y sacar partido al ganado y a los útiles de labranza heredados y por partir ${ }^{42}$.

Sólo así la vida cotidiana de aquellos menores huérfanos, reflejada en las cuentas de curaduría dadas por sus tutores, aparecerá más nítida, advirtiendo sobre gastos de escuela y aprendizajes sociales privilegiados. Informando, a la par y también, respecto a la cura de enfermedades, viajes y el cambiante mundo de la moda y el vestuario.

\section{Algunas conclusiones}

Inmersos en una confluencia de intereses comunitarios afines, la necesidad de defender la supervivencia y los patrimonios de los menores se fue incrementando en la Castilla interior durante el Antiguo Régimen; también, y fundamentalmente, en los espacios rurales campesinos. Entonces, la participación familiar muy próxima aumentó, en muchas ocasiones las mismas madres, tratando de proteger el mundo juvenil hasta su mayoría de edad.

Las actuaciones de buenos y malos tutores se sucedían. Nos constan los litigios suscitados en no pocas ocasiones, significando que la tenencia de la tierra se convertía con frecuencia en cuestión de pleito familiar. Así, ante los tribunales se desplazaron bastantes curadores para salvaguardar capitales o para acusar de unas nefastas gestiones contables con consecuencias muy negativas para las posibilidades de desenvolvimiento presente y futuro de aquellos jóvenes implicados.

Desde esas perspectivas surgen vitales unas prácticas populares que invitan a la reflexión sobre este capítulo clave, aunque todavía necesitado de muchos más estudios profundos y desde ópticas multidireccionales, de la historia social moderna.

Y desde el amplio conjunto de fuentes documentales analizadas que implicaban tanto a menores como a sus administradores, cabe empezar a rastrear con un mayor nivel de conocimiento las condiciones materiales e inmateriales de esa etapa fundamental del ciclo vital familiar. En resumen, afloran entonces pagos de medicinas, salarios de criadas, gastos de manutención, aportes dotales adelantados, viajes de estudios, pupilajes, hechuras de los sastres y de las piezas del vestuario

42. En la almoneda de los menores Alonso y María Barrera, celebrada en Villacelama (León), en 1770, se vendieron «un buey negro en 418 reales de vellón, otro castaño en 276 rls., una yegua con un macho en 1.180 rls., dos novillos en 335 rls. y diecisiete reses lanares en 361 rls.»; Archivo Histórico Provincial de León, Secc. Prot., caja 740. 
MÁXIMO GARCÍA FERNÁNDEZ

TUTELA Y MINORÍA DE EDAD EN LA CASTILLA RURAL: PRÁCTICAS COTIDIANAS DE ANTIGUO RÉGIMEN

imprescindibles más características en sus distintas calidades, junto a más de un par de zapatos y algún sombrero. Tanto unas nulas demandas como ciertos desembolsos consumistas para la satisfacción de sus necesidades y/o unas renovaciones textiles que reflejan ritmos de reposición más activos de lo que siempre se ha pensado y no tan limitados dentro de aquella vida cotidiana popular castellana. ¿Tales contrastes muestran la propia voluntad de cada joven o prevalecían en dichos comportamientos económico-culturales los intereses de sus tutores?

La casuística es muy amplia. Picaresca e inversión en formación; atenciones tutoriales y desfalcos manifiestos; demostraciones públicas, inversiones lúdicas o lucimiento externo; la alimentación diaria por encima de las compras de unos decentes vestuarios o de cualquier otra consideración educativa.

La mayor parte de lo proporcionado a la vida material juvenil, tanto en alimentos como en ropajes, no puede caracterizarse como de un buen trato modernizador. Sus arcas y casas necesitaban más y nuevos equipamientos textiles y formativos.

En cualquier caso, la vida cotidiana de aquellos menores huérfanos aparece aquí clarificada y abierta a nuevas investigaciones.

\section{BibLIOgRAFÍA}

Ago, R.: «Jóvenes nobles en la época del absolutismo: autoritarismo paterno y libertad», en Levi, G. y Schмiтt, J. C. (Dirs.): Historia de los jóvenes, vol. I: De la Antigüedad a la Edad Moderna. Madrid, 1996, pp. 365-413.

ARı̀̀s, Ph.: El niño y la vida familiar en el Antiguo Régimen. Madrid, 1987 (1. ${ }^{a}$ edición 1960). Bouneau, Ch. y Le Mao, C. (Dirs.): Jeunesse(s) et élites. Des rapports paradosaux en Europe de l'Ancien Régime à nos jours. Rennes, Presses Universitaires de Rennes, 2009.

Cava López, M. ${ }^{a}$ G.: «Economías infantiles: recursos materiales y gestión del patrimonio de los huérfanos extremeños durante la Edad Moderna», Obradoiro, 8, 1999, pp. 91-97.

Cava López, M. ${ }^{a}$ G.: «La protección familiar a la infancia desamparada: huérfanos en Extremadura en tiempos de Felipe II», en Martínez RuIz, E. (Dir.): Madrid, Felipe II y las ciudades de la Monarquía. Madrid, 2000, pp. 83-96.

Cava López, M. ${ }^{a}$ G.: «La tutela de los menores en Extremadura durante la Edad Moderna», Revista de Historia Moderna, 18, 2000, pp. 265-288.

Cava López, M. ${ }^{a}$ G.: «Niños e infancia en la investigación sobre la Edad Moderna: el abandono de una historia de abandonos», en Alvar Ezquerro, A., et al. (Eds.): Política y cultura en la época Moderna. Alcalá de Henares, 2004, pp. 751-761.

Dubert García, I.: Historia de la Familia en Galicia durante la época Moderna, 15501830. La Coruña, 1992.

Fass, P. S. (Ed.): The Encyclopedia of the History of Childhood. Nueva York, 2003.

García Fernández, M.: Herencia y patrimonio familiar en la Castilla del Antiguo Régimen (1650-1834): efectos socioeconómicos de la muerte y la partición de bienes. Valladolid, 1995. 
MÁXIMO GARCÍA FERNÁNDEZ

TUTELA Y MINORÍA DE EDAD EN LA CASTILLA RURAL: PRÁCTICAS COTIDIANAS DE ANTIGUO RÉGIMEN

García Fernández, M.: «Tutorías y cuentas de gastos de menores: consumos juveniles diferenciados en la Castilla del Antiguo Régimen», en Muñoz Navarro, D. (Ed.): Comprar, vender y consumir. Nuevas aportaciones a la bistoria del consumo en la España moderna. Valencia, 2011, pp. 123-152.

Herrero Jiménez, M.: Padrones y registros notariales medievales abulenses en el Archivo de la Real Chancillería de Valladolid. Ávila, 2010.

Kertzer, D. I. y Barbagli, M. (Comps.): Historia de la familia europea, vol. I: La vida familiar a principios de la era moderna (1500-1789). Barcelona, 2002.

Levi, G. y Schmitt, J. C. (Dirs.): Historia de los jóvenes, vol. I: De la Antigüedad a la Edad Moderna. Madrid, 1996.

Lorenzo Pinar, F. J.: «La familia y la herencia en la Edad Moderna zamorana a través de los testamentos», Studia Historica. Historia Moderna, 9, pp. 159-201.

Mantecón Movellán, T. A.: Conflictividad y disciplinamiento social en la Cantabria rural del Antiguo Régimen. Santander, 1997.

Merchán Álvarez, A.: La tutela de los menores en Castilla hasta fines del siglo XV. Sevilla, 1976.

NúÑEz RoldÁn, F.: «Fuentes y metodología para el estudio de la infancia rural: las tutelas y las cuentas de menores en los siglos XVI y XviI», en NúÑEz Roldán, F. (Ed.): La infancia en España y Portugal. Siglos XVI-XIX. Madrid, 2011, pp. 133-148.

Pierrer, S., «Roles des réseaux de parenté dans l'education des mineurs orphelins selon les comptes de tutelle parisiens (xvire-XviIIe siécles)», Annales de Démographie Historique, 1995, pp. 125-135.

Redondo, A. (Ed.): La formation de l'enfant en Espagne aux XVIe et XVIIe siècles. París, 1996.

Roberts, B.: “'Wearing Out a Pair of Fool's Shoes'. Sexual Advice for Youth in Holland's Golden Age», Journal of the History of Sexuality, 13, 2004, pp. 139-156.

Roberts, B.: «The 'Marlboro Men' of the Early Seventeenth-Century. Masculine Role Models for Dutch Youths in the Golden Age?», Men and Masculinities, 9 (julio 2006), pp. 76-94.

Roberts, B. y Groenendijk, L.: “'Moral Panic and Holland's Libertine Youth of the 1650s and 1660s», Journal of Family History, 30, 2005, pp. 327-346.

Rodríguez SÁnchez, Á.: «El poder familiar: la Patria Potestad en el Antiguo Régimen», Crónica Nova, 18, 1990, pp. 365-380.

SaAvedra Fernández, P.: La vida cotidiana en la Galicia del Antiguo Régimen. Barcelona, 1994. 